\title{
INFLUENCE OF THE LIMBIC SYSTEM ON OVULATION AND ON PROGESTERONE AND ESTROGEN FORMATION IN RABBIT'S OVARY
}

\author{
Masazumi Kawakami, Katsuo Seto \\ AND Kazuchika YoshidA \\ Second Department of Physiology, Yokohama University \\ School of Medicine, Yokohama
}

The regulation of pituitary-gonadal function by the central nervous system has been the subject of many studies, most of which deal with the hypothalamus.

Recently several studies have been developed on the effect of the activity of the amygdala upon ovulation and the ovarian progesterone output $t^{1,2,3,4,5,6)}$. Yet the effect of electrical stimulation of the hippocampus upon the inducement of ovulation remains to be investigated. Furthermore, there have been no reports, to our knowledge, on the mechanisms controlling biosynthesis of steroid hormones in the ovary and on the relation between their synthesis and release. Such mechanisms need to be understood because seesaw relationship of the electrical activity was observed between the amygdala and the hippocampus during estrus, ovulation and pregnancy in our previous experiments. For example, the EEG activity of the hippocampus decreased during estrus and after copulation-induced ovulation while the EEG activity of the amygdala showed gradual increase with the advance of estrus, and decrease after copulation-induced ovulation ${ }^{7,8}$. Because of these differences authors may speculate that the hippocampus contributes to the regulation mechanism affecting the gonadotrophin secretion of the adenohypophysis through the hypothalamus in a different manner from the amygdala. The purpose of the present experiment is twofold. The first goal is to elucidate the different influences of electrical stimulation of critical areas in the limbic system upon the progesterone and estrogen formation in the ovary and ovarian progesterone output of the rabbit. This will be accomplished through observations upon the incorporation of radioactivity into progesterone and estrogen by the ovarian homogenates in vitro with $\left(1-{ }^{14} \mathrm{C}\right)$ acetate. The second goal will be to confirm the existence of a positive feedback control loop between the

Received for publication November 4, 1965

川上正澄, 瀬户勝男, 吉田三知 
hippocampal activity and the ovarian progesterone formation and its output, as well as the existence of a negative feedback control loop between the amygdalar activity and the ovarian progesterone formation and output.

\section{MATERIALS AND METHODS}

Sexually mature female New Zealand White rabbits $(2.5-3.2 \mathrm{~kg}$ ) were fed on an artificial diet supplemented periodically with fresh greens and carrots and were kept under natural lighting conditions. They were isolated in individual cages for at least three weeks before use.

Stimulation, recording, and lesioning were accomplished by means of permanent electrodes stereotaxically placed in the hypothalamus and several parts of the limbic system as well as the hippocampus with the aid of rabbit brain atlas ${ }^{9}$. The electrode assembly consisted of a 9-place minute socket with connected bipolar concentric stainless steel insulated electrodes enclosed in acrylic resin. The electrode assembly was fixed directly to the skull with acrylic resin and secured in addition by cementing it to 4 stainless steel screws fixed in the skull.

Stimulation consisted of monophasic square wave pulses delivered unilaterally with a Sanei Stimulator (ES-103-Y) and isolation unit for $30 \mathrm{~min} ., 60 \mathrm{sec}$. on and $60 \mathrm{sec}$. off, 250 to $280 \mu \mathrm{A}$, at $0.1 \mathrm{msec}$. duration, $60 \mathrm{cps}$. Current flow was monitored with a radiopulse transformer and oscilloscope, and the EEG activity of the brain was recorded during both stimulation and inter-stimulation periods on a Sanei electroencephalograph (EG-908) to detect whether or not a EEG seizure pattern was induced by the stimulation.

In order to determine the possible nervous pathways from the hippocampus to the hypothalamus which might control the pituitary gonadotrophic function, lesions were made in the bilateral dorsal or ventral fornix, septum and the bilateral stria terminalis by electrocoagulation with radio frequency waves between a lesioning electrode tip as anode and an indifferent plate electrode placed in contact with the abdomen. The small lesions of the periventricular arcuate nucleus were produced electrolytically with a direct current of $4 \mathrm{~mA}$ for 30 seconds.

Stimulation experiments were made after a three-week period permitting recovery from cerebral edema.

The implanted rabbits were primed with estradiol benzoate in oil ( $0.1 \mathrm{mg}$ s.c.) for two days prior to stimulation to ensure an estrous state after the three week recovery period. Electrical stimulation was delivered without anesthesia. A laparotomy was performed after local anesthesia of the abdominal muscle with 1 percent novocaine and blood was collected for $10 \mathrm{~min}$. from the vein of one side of ovary and the auricular artery, beginning at $45 \mathrm{~min}$. after the stimulation. This ovary was removed from the body $7 \mathrm{~min}$. later, in order to determine the incorporative rates of progesterone and estrogen (estradiol and estrone) from $\left(1-{ }^{14} \mathrm{C}\right)$ acetate. Further, the ovary of the other side was observed to check ruptured ovarian follicles at a re-laparotomy under pentobarbital anesthesia some 48 hours later.

Incubation of the ovarian homogenates was carried out in $50 \mathrm{ml}$ Erlenmeyer flasks. $100 \mathrm{mg}$ of the ovarian homogenates, $5 \mathrm{ml}$ of Krebs-Ringer phosphate buffer at $\mathrm{pH} 7.2$, and $10 \mu$ moles $(0.3 \mu \mathrm{c})$ of sodium $\left(1-{ }^{-14} \mathrm{C}\right)$ acetate (Isotope Specialities, U.S. A.) were added to each flask. The flasks were closed and shaken for $60 \mathrm{~min}$. in $37^{\circ} \mathrm{C}$ by a Taiyo incubator. After incubation, the progesterone, estradiol and estrone in the reaction mixture were separated by the method of Seto, Sekiguchi, Ushikoshi and $\mathrm{UMEZU}^{10)}$ and the total radioactivity in each of these fractions was measured by the 
method of Roberts, SETo and HANking ${ }^{11}$. The progesterone in the blood was analyzed quantitatively by the method of SETO et al.10). Namely, for separation and determination of the progesterone, estradiol and estrone, each of carrier steroids or radio-active steroids (for internal standard) was added to the incubation medium of the ovarian homogenates or blood and the mixture was extracted with ether. The residue of the ether extract was partitioned between ligroin (boiling range $65-110^{\circ} \mathrm{C}$ ) and $90 \%$ aqueous methanol. The aqueous methanolic phase containing the polar lipid fraction was evaporated and the steroids were extracted from the water phase with benzene. The phenolic steroid fraction was separated from the neutral fraction by shaking the benzene solution with $1 \mathrm{~N}$ sodium hydroxide. The neutral fraction was further purified on a silicic acid column chromatography eluting the steroids with benzene containing increasing proportions of ethyl acetate. The neutral steroids were then separated on silicic acid thin layer chromatography in the ligroin/propylen glycol system. The zone of the progesterone was eluted from the thin layer, and was acetylated by pyridine and acetic anhydride. The acetylated progesterone was further purified by gasliquid chromatography (argon ionized detector, SE-30, $245^{\circ} \mathrm{C}$ ). The phenolic steroid fraction was separated on a silicic acid thin layer chromatography in the toluene/propylene glycol system. The zones of estradiol and estrone were eluted from the thin layer, and were acetylated with pyridine and acetic anhydride. The acetylated estradiol and estrone were further purified by gasliquid chromatography (argon ionized detector, $\mathrm{SE}-30,245^{\circ} \mathrm{C}$ ). Total radioactivity in progesterone, estradiol and estrone was measured by using $5 \mathrm{ml}$ of a scintillation system in toluene containing $0.5 \%$ PBD (phenylbiphenyloxadiazole) and 0.01\% POPOP (1, 4-bis-2(5-phenyloxazoly)benzene). Counting was carried out in the liquid scintillation spectrometer. The ovarian progesterone output was estimated by the differences in amounts of progesterone between arterial and venous blood.

In autopsy, brains were fixed in $10 \%$ formalin and the precise locations of electrode tips were determined histologically.

\section{RESULTS}

The results of unilateral electrical stimulation applied through chronically implanted electrodes within the limbic system were as follows:

1) Effects of hippocampal stimulation upon ovulation. Positive results with ovulation or large hemorrhagic follicles as evidence of subovulatory gonadotrophic stimulation, in response to the $260-280$ or $390-400 \mu$ A electrical stimulation of the hippocampus, were obtained in 20 cases among 30 estrous rabbits as shown in TABLE 1.

Almost no significant changes in somato-motor responses were observed in $260-280 \mu \mathrm{A}$ electrical current stimulation of this region except for transient pupil dilation, occasional searching behavior, and gazing forward. The first or second inter-stimulus EEG patterns as well as those during the stimulation revealed an occasional localized brief seizure pattern or propagated seizure wave to the amygdala and some other regions as shown in FIG. 1.

Furthermore, when $390-400 \mu \mathrm{A}$ stimuli were applied to several parts of the hippocampus, more obvious seizure patterns in the EEG were observed 
FC

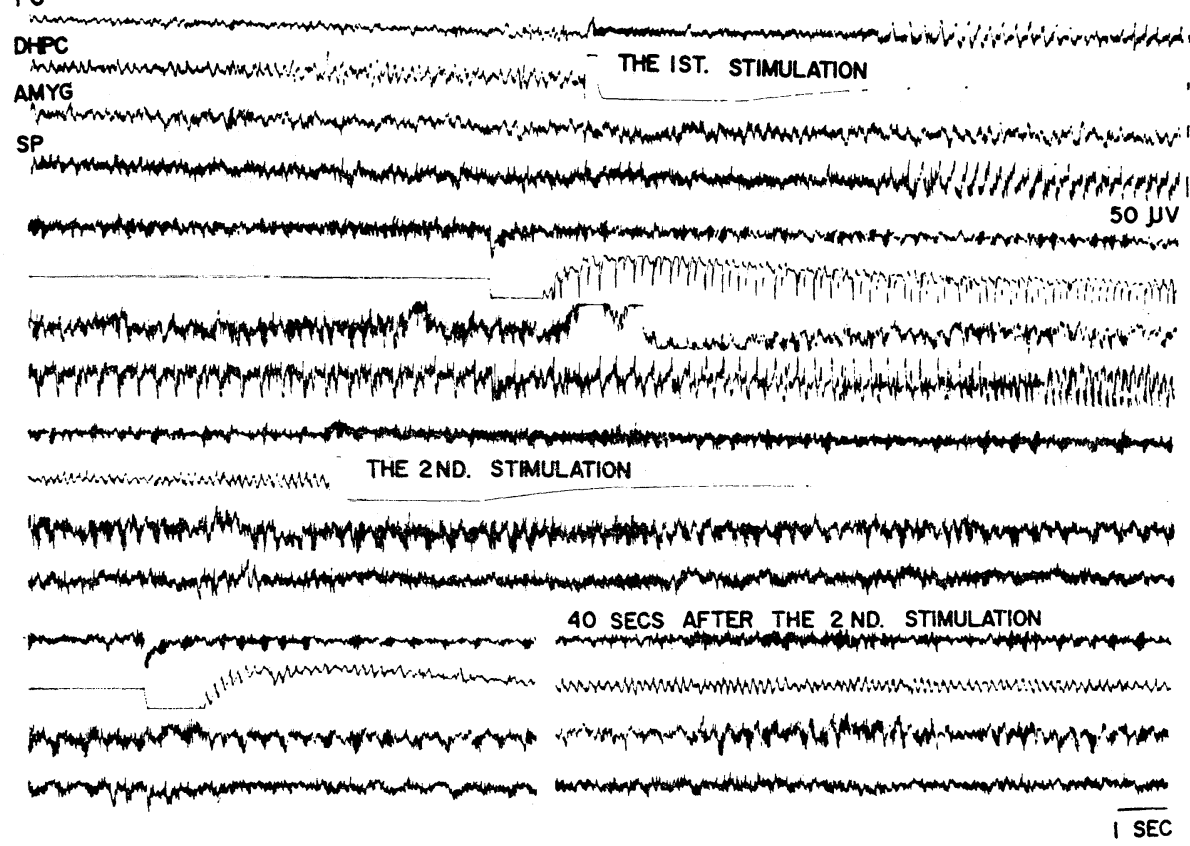

FIG. 1. Comparison of EEG patterns on several parts of brain between, before and immediately after stimulation of the dorsal hippocampus. Abbreviations: FC: Frontal cortex. DHPC: Dorsal hippocampus. AMYG: Amygdala. SP: Septum.

in several parts during and after the first, second or later stimulations.

Low current levels of $60 \mathrm{cps}$ electrical stimulation usually suppressed the hippocampal EEG activity, while the same frequency elevated the hippocampal EEG activity with higher stimulus currents $(260-280 \mu \mathrm{A})$.

Little difference was observed between the dorsal and the ventral hippocampus in the stimulatory effect of inducing ovulation. FIG. 2 represents the schematic representation of the sites within the hippocampus, which elicited or failed to induce ovulation when stimulated. On the other hand, among 11 rabbits with electrodes in several parts of the amygdala, positive results were obtained only in 5 rabbits with electrode tips located in the medial amygdaloid nucleus as shown in TABLE 1 . This fact was in accord with the findings by KoIKEgAmi et al. ${ }^{1)}$, and SAWYER ${ }^{4}$.

Positive results were also obtained in the estrous rabbits which were electrically stimulated with 280 or $400 \mu \mathrm{A}$ at the periventricular arcuate nucleus and the posterior median eminence as indicated in TABLE 1. Ten rabbits with electrodes in the lateral hypothalamus, medial forebrain bundle, and the habenula, failed to ovulate in response to electrical excitation. On the other hand, stimulation of the dorsomedial and posterior hypothalami or the mammillary body exerted such stimulatory effects as production of hemorrhagic 


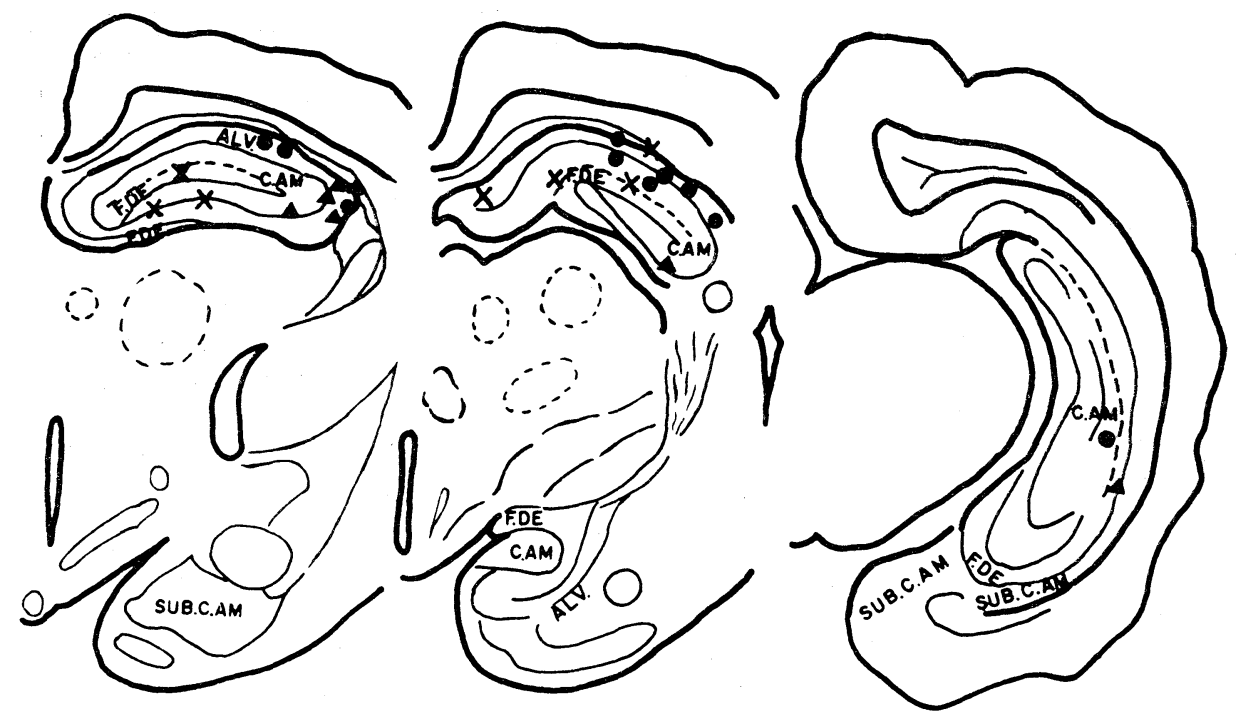

FIG. 2. Transverse reconstruction of rabbit hippocampus indicating the extent of area which resulted in ovulation when stimulated. Note: In many ovulation positive cases the tips of electrodes were situated at the layers of polymorphic cells, large pyramids and radiations, while in negative cases, they ware situated at fascia dentata. Crosses represent the areas where ovulation failed to occur on stimulation. Closed circles indicate the points where stimulation caused ovulation, and triangles, the points where stimulation induced large hemorrhagic follicles. Abbreviations: ALV: Alveus. C. AM: Cornus Ammonis. F. DE: Fascia Dentata. SUB. C. AM: Subiculum Cornu Ammonis.

follicles in the ovary.

KoIKegAmi ${ }^{1)}$, EvereTT ${ }^{2)}$, Shealy et al..$^{3)}$ and SAWYER ${ }^{4)}$ demonstrated that ovulation could be induced by stimulating the medial nucleus of the amygdala in rabbits, rats, and cats. These and other studies made it apparent to a certain degree that the amygdala was involved in the control mechanism of sexual behavior and the release of ovulatory hormone ${ }^{12,13,14,15)}$. Moreover, an intimate anatomical and electrophysiological connections between the amygdala and the hypothalamus has been proved ${ }^{16,17,18,19,20,21)}$. According to KAWAKAMI's observation, there is, also, the fact that the seizure pattern produced by 60 cps high current electrical stimulation of the dorsal or ventral hippocampus spreads more easily to the amygdala, septum, cerebral cortex, and the midbrain reticular formation than to any other regions of the rabbit's brain. There is, therefore, the possibility that the ovulation induced by electrical stimulation of the hippocampus in the present experiment is due to the spread of the hippocampal stimulation effect to the amygdala.

In an attempt to determine the pathway through which the impulses of the activated hippocampus reach the posterior basal hypothalamus and thereby 


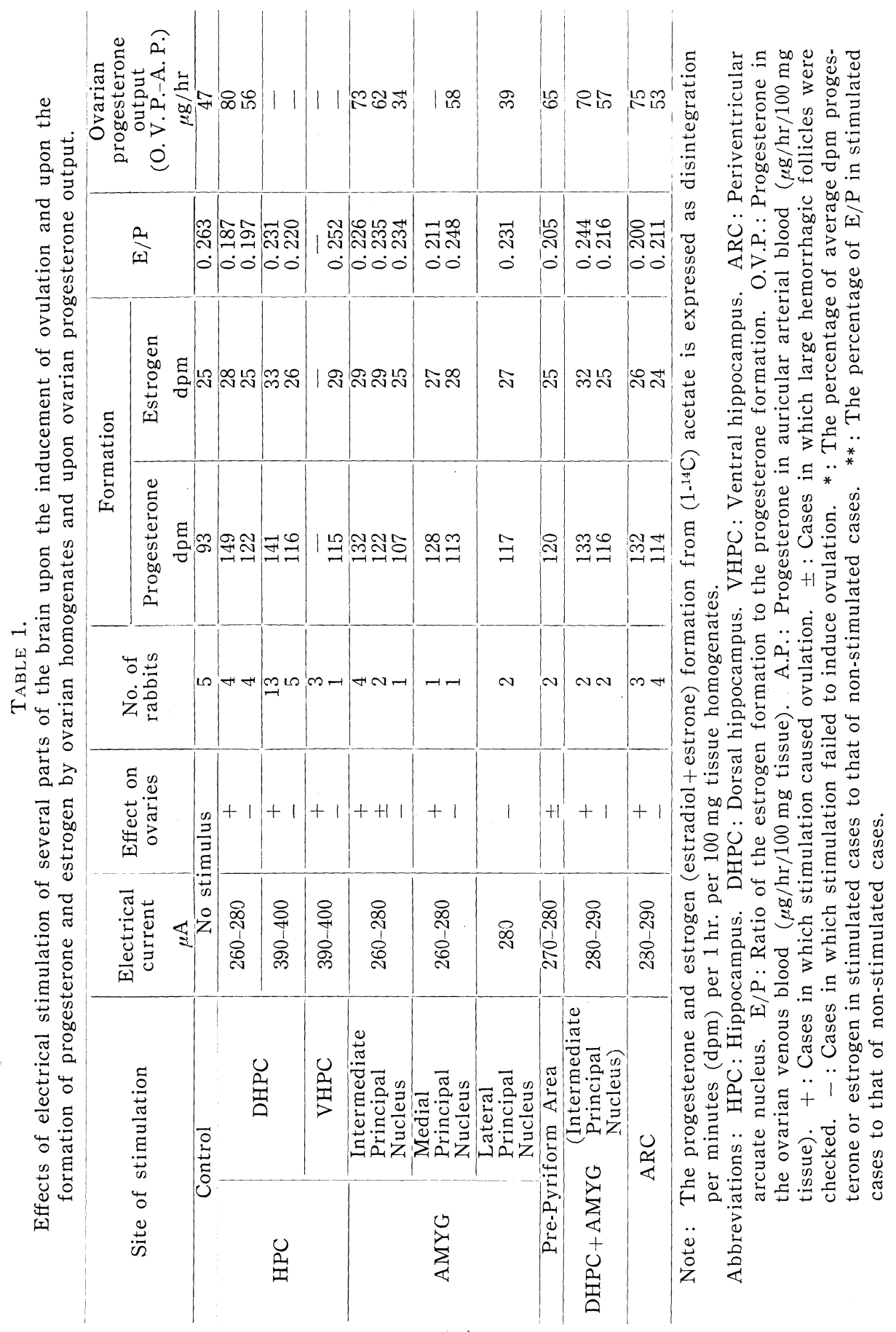


induce ovulation, destructive lesions were made in the fornix, septum and the stria terminalis. Rabbits with bilateral massive lesions of the dorsal or ventral fornix including adjacent regions, or of the septum failed to ovulate in response to 280 or $400 \mu \mathrm{A}$ electrical stimulation of the appropriate area in the hippocampus as illustrated in TABLE 6.

FIG. 3A shows an example illustrating the sites and sizes of the fornical lesions. FIG, 3B shows a composite diagram of the bilateral massive destruction of the dorsal or ventral fornix associated with both decreased ovarian progesterone, estradiol and estrone production and output. The dark shading in the figure indicates the destroyed area involving the dorsal fornix and the thalamus (left), and the ventral fornix and the adjacent region (right). On the other hand, large hemorrrhagic follicles were found to be induced by electrical stimulation of the hippocampus after the bilateral lesioning of the

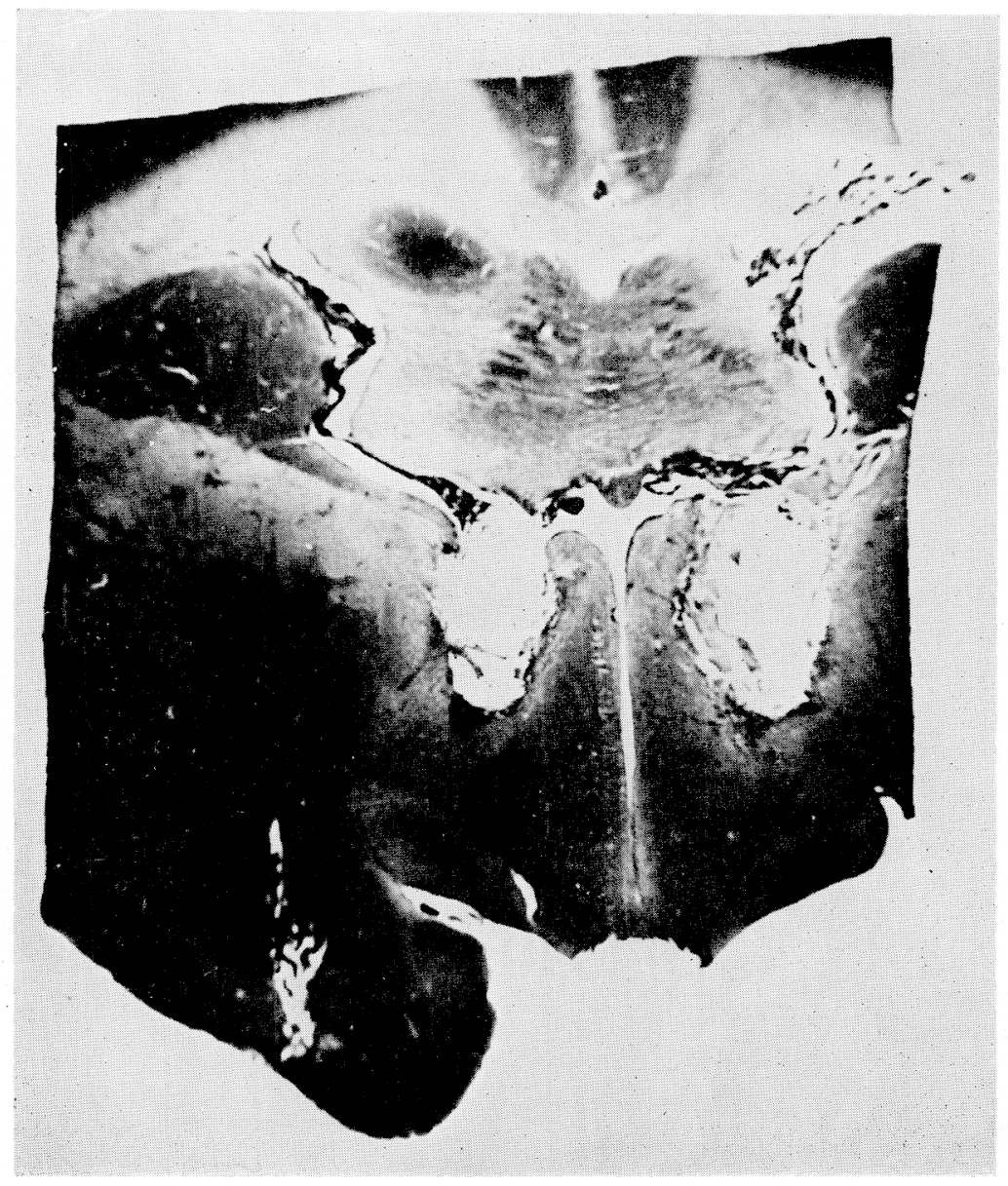

(A) 

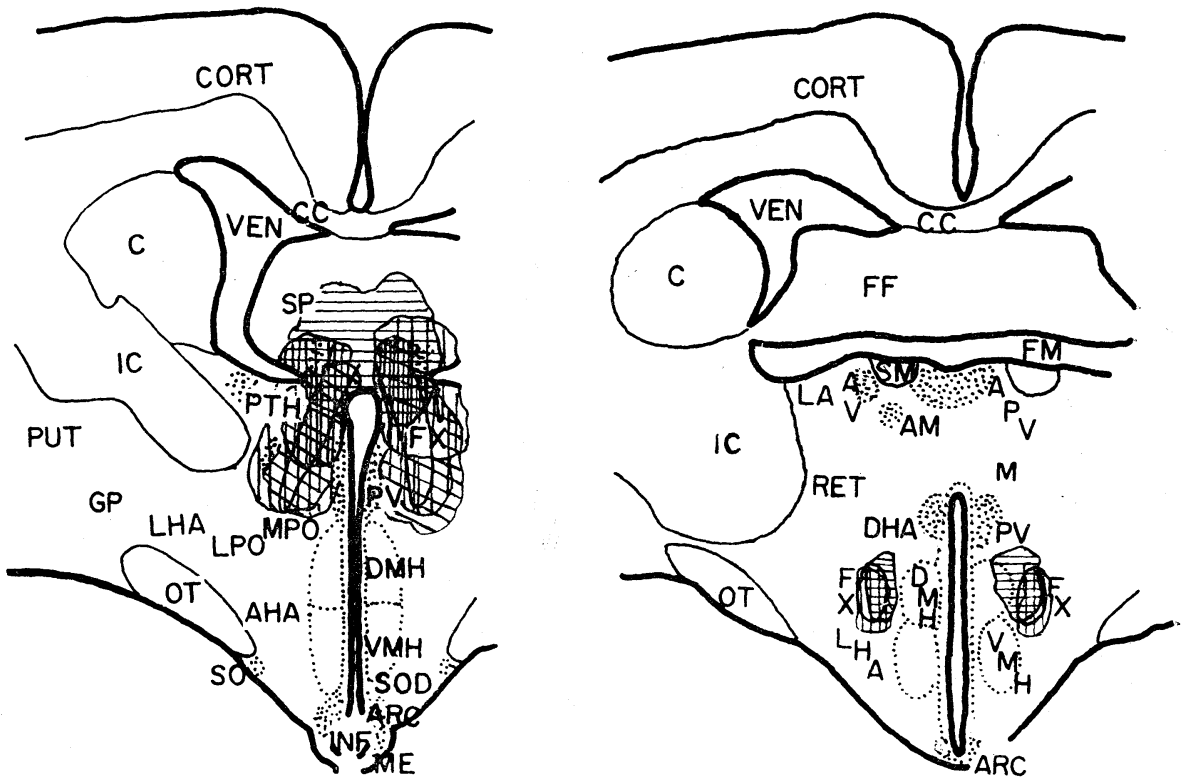

(B)

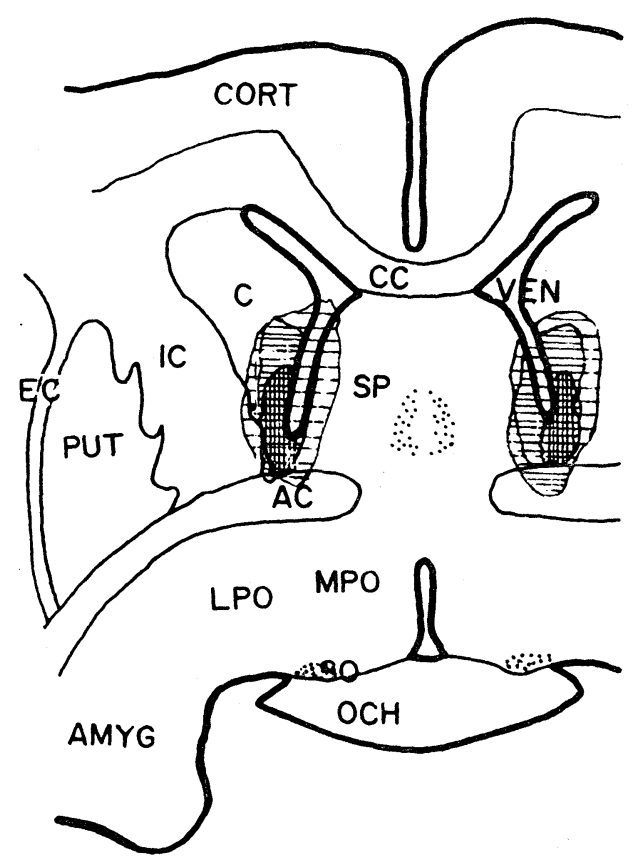

FIG. 3. (A) An example of the fornical lesions effective in blocking ovulation and in depressing ovarian progesterone production and output by hippocampal electrical stimulation. (B) Reconstruction of lesions on coronal section of the dorsal (left) and the ventral (right) fornix. Sites of the fornix lesions in 6 rabbits in which ovulation failed to occur on the hippocampal stimulation. (C) Reconstruction of lesions on coronal section of the stria terminalis. Site of lesions involving the stria terminalis in 3 . rabbits in which large hemorrhagic follicles were induced by the hippocampal stimulation.

Abbreviations :

////: Inclusive area destroyed by lesions.

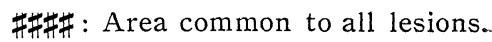

(C) 
stria terminalis in three rabbits. Further, three rabbits with lesions of the periventricular arcuate nucleus including adjacent regions failed to ovulate in response to $280 \mu \mathrm{A}$ electrical stimulation of the appropriate area in the hippocampus.

These results indicate that the hippocampus is directly connected with the periventricular arcuate nucleus. There is also an anatomical evidence that assists the existence of direct efferent connection from the hippocampus to the periventricular arcuate nucleus ${ }^{22}$.

Therefore, ovulation induced by electrical stimulation of the hippocampus without eliciting a general seizure might be mainly due to a direct influence exerted upon the periventricular arcuate nucleus, with little or no effect upon activation of the amygdala, through the pathway from the activated hippocampus to the periventricular arcuate nucleus.

2) Progesterone and estrogen formation in the ovary and ovarian progesterone output by electrical stimulation of the hippocampus of the rabbits. In the cases in which ovulation (along with ruptured ovarian follicles) was induced by 260-280 $\mu$ A electrical stimulation of the dorsal hippocampus, progesterone labelling from $\left(1{ }^{14} \mathrm{C}\right)$ acetate by the ovarian homogenates increased by 60 per cent and the ovarian progesterone output increased by 70 per cent as compared with the non-stimulated cases. Further, slightly increased $\left({ }^{14} \mathrm{C}\right)$-estrogen (estradiol +estrone) formation by the ovarian homogenates was revealed in the positive cases of induced ovulation by hippocampal stimulation. Therefore, the ovulation-positive cases produced by hippocampal stimulation showed a decrease of 29 per cent in the ratio of $\left({ }^{14} \mathrm{C}\right)$-estrogen to $\left({ }^{14} \mathrm{C}\right)$-progesterone from $\left(1-{ }^{14} \mathrm{C}\right)$ acetate (E/P ratio) when compared with the control cases. Furthermore, in the rabbits, in which ovulation was not induced by the hippocampal stimulation, the progesterone formation from $\left(1{ }^{-14} \mathrm{C}\right)$ acetate in the ovarian homogenates was increased by 31 per cent compared with that of the control group. The progesterone output from the ovary was likewise increased by 19 per cent.

Thus, electrical stimulation of the dorsal hippocampus exerted a facilitatory influence on progesterone formation in the ovary both in ovulated and non-ovulated cases, and there was seen also a facilitatory effect in estrogen formation in the ovulated cases though in a less degree, while no significant difference was recognized in estrogen formation as compared with the control in the non-ovulated cases. These results are summarized in TABLE 2.

In the cases in which ovulation was produced by $260-280 \mu \mathrm{A}$ electrical stimulation of the intermediate nucleus of amygdala, it was found that $\left({ }^{14} \mathrm{C}\right)$ progesterone formation from $\left(1{ }^{14} \mathrm{C}\right)$ acetate by the ovarian homogenates was increased (as in the cases of $260-280 \mu \mathrm{A}$ stimulation of the dorsal hippocampus) by 42 per cent as compared with the non-stimulated cases. An increase of 


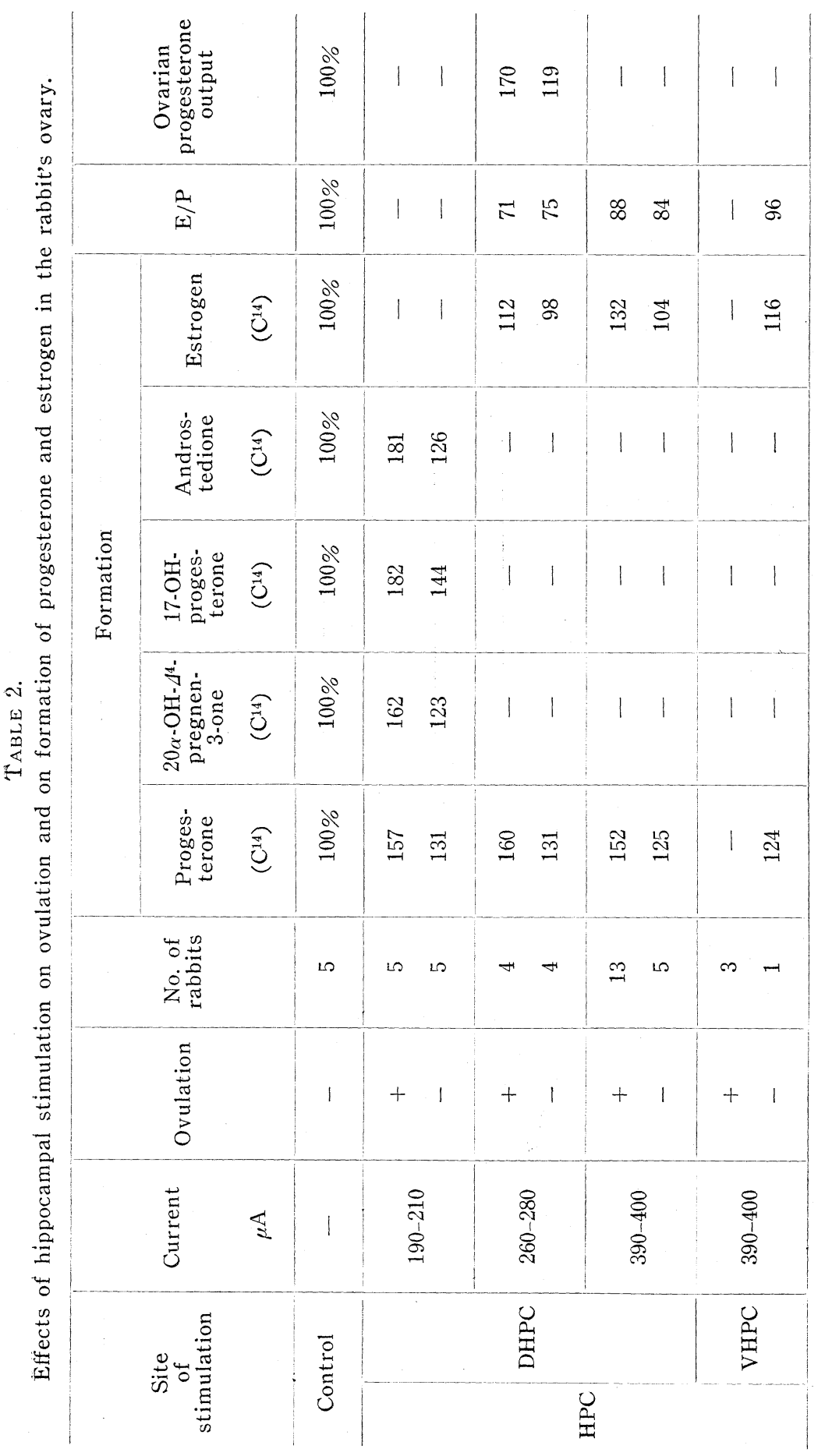


16 per cent was observed in estrogen labelling, therefore the $\mathrm{E} / \mathrm{P}$ ratio decreased by 14 per cent. A marked increase of 55 per cent was observed in the ovarian progesterone output as seen in TABLE 3 .

TABLE 3.

Effects of amygdaloid stimulation on ovulation and on formation of progesterone and estrogen in the rabbit's ovary.

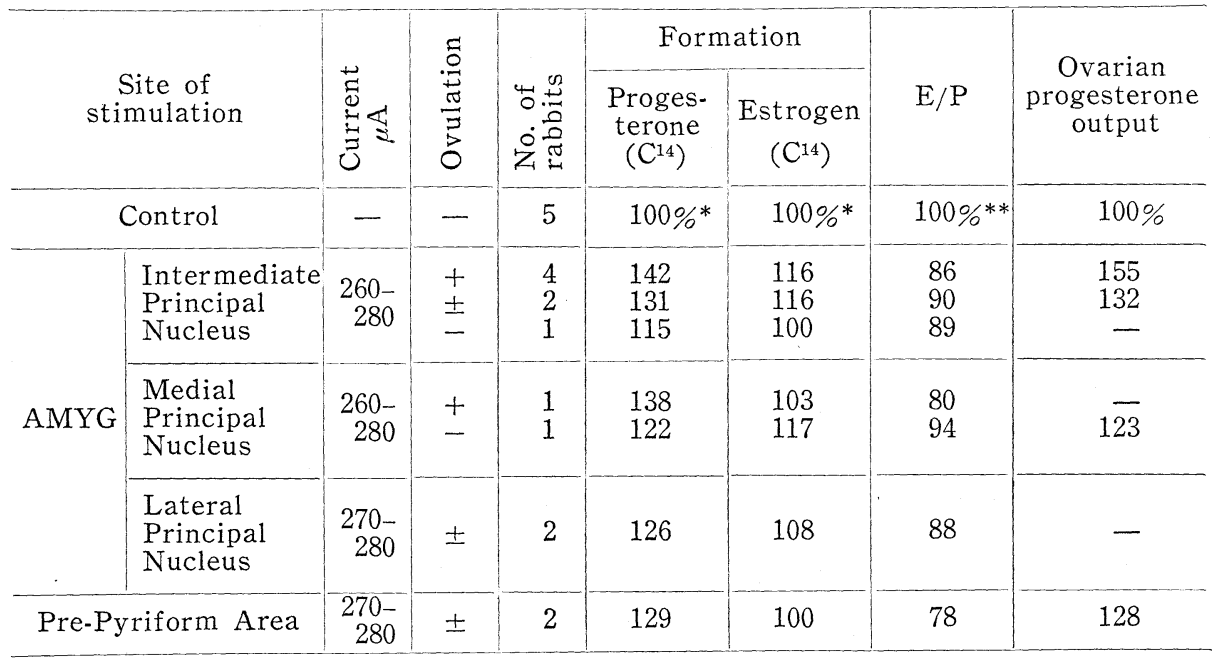

Progesterone labelling from $\left(1-1^{14} \mathrm{C}\right)$ acetate by the ovarian homogenates increased by 42 per cent as an effect of $280-290 \mu \mathrm{A}$ electrical stimulation of the arcuate nucleus, but no change occurred in the estrogen formation and so the $\mathrm{E} / \mathrm{P}$ ratio took the value 24 per cent lower as compared with the control. The level of the ovarian progesterone output was 60 per cent higher than the control as shown in TABLE 4.

TABLE 4.

Effects of electrical stimulation of periventricular arcuate nucleus on ovulation and on formation of progesterone and estrogen in the rabbit's ovary.

\begin{tabular}{c|c|c|c|c|c|c|c}
\hline $\begin{array}{c}\text { Site of } \\
\text { stimulation }\end{array}$ & $\begin{array}{c}\text { Current } \\
\mu \mathrm{A}\end{array}$ & Ovulation & $\begin{array}{c}\text { No. of } \\
\text { rabbits }\end{array}$ & $\begin{array}{c}\text { Proges- } \\
\text { terone } \\
\left(\mathrm{C}^{14}\right)\end{array}$ & $\begin{array}{c}\text { Estrogen } \\
\left(\mathrm{C}^{14}\right)\end{array}$ & E/P & $\begin{array}{c}\text { Formation } \\
\text { Ovarian } \\
\text { progesterone } \\
\text { output }\end{array}$ \\
\hline Control & - & - & 5 & $100 \% *$ & $100 \% *$ & $100 \% * *$ & $100 \%$ \\
\hline ARC & $280-290$ & + & 3 & 142 & 104 & 76 & 160 \\
\hline & 400 & + & 1 & 123 & 96 & 80 & 113 \\
\hline
\end{tabular}


To compare the effects of hippocampal stimulation with those of amygdalar stimulation, in both of which $260-280 \mu \mathrm{A}$ current was employed and ovulation resulted, the former brought about a higher degree of formation of $\mathrm{C}^{14}$-incorporated progesterone from $\left(1{ }^{14} \mathrm{C}\right)$ acetate than the latter by 13 per cent, while no significant difference existed in estrogen formation, thus resulting a lower $\mathrm{E} / \mathrm{P}$ ratio by 17 per cent. The ovarian progesterone output was also higher in the former case by 10 per cent.

Further, progesterone labelling from $\left(1-{ }^{14} \mathrm{C}\right)$ acetate by the ovarian homogenates and the ovarian progesterone output in the ovulation-positive cases by $280 \mu \mathrm{A}$ hippocampal stimulation were higher than in the case of arcuate nucleus stimulation, 13 per cent and 6 per cent respectively, and the E/P ratio was 7 per cent lower. The $260-280 \mu \mathrm{A}$ electrical stimulation of the hippocampus, therefore, is different in the ovulated cases from that of the amygdala (N. intermediate) and the periventricular arcuate nucleus, in respect to the progesterone labelling from $\left(1-{ }^{14} \mathrm{C}\right)$ acetate by the ovarian homogenates, ovarian progesterone output, and the ratio of $\mathrm{E} / \mathrm{P}$; while only a small difference is found to exist between the latter two as in TABLE 5.

TABLE 5.

Effects of electrical stimulation of the dorsal hippocampus, amygdala and the periventricular arcuate nucleus upon production of ovarian progesterone in ovulated rabbits.

\begin{tabular}{c|c|c|c|c|c}
\hline $\begin{array}{c}\text { Site of } \\
\text { stimulation }\end{array}$ & $\begin{array}{c}\text { Current } \\
\mu \mathrm{A}\end{array}$ & $\begin{array}{c}\text { No. of } \\
\text { rabbits }\end{array}$ & $\begin{array}{c}\mathrm{C}^{14} \text {-incorporated } \\
\text { to progesterone }\end{array}$ & $\mathrm{E} / \mathrm{P}$ & $\begin{array}{c}\text { Progesterone } \\
\text { output }\end{array}$ \\
\hline Control & - & 5 & $100 \% *$ & $100 \% * *$ & $100 \%$ \\
\hline DHPC & $260-280$ & 4 & 160 & 71 & 170 \\
\hline ARC & $390-400$ & 13 & 152 & 88 & - \\
\hline AMYG & $280-290$ & 3 & 142 & 76 & 160 \\
\hline
\end{tabular}

Furthermore, in the ovulated cases produced by hippocampal stimulation with higher currents in the range of $390-400 \mu \mathrm{A}$ progesterone labelling from $\left(1^{-14} \mathrm{C}\right)$ acetate by the ovarian homogenates increased 52 per cent as compared to the non-stimulated cases. This change was similar to the case of 260-280 $\mu \mathrm{A}$ hippocampal stimulation. However, the formation of $\mathrm{C}^{14}$-incorporated estrogen was higher than in the case of the $260-280 \mu \mathrm{A}$ hippocampal stimulation; the former revealing a 20 per cent increase in the $\mathrm{E} / \mathrm{P}$ ratio as compared with the latter. Therefore, the differences between the $\mathrm{E} / \mathrm{P}$ ratios after high current hippocampal stimulation and after low current hippocampal stimulation might be due to the differed state of excitabilities in the amyg- 
dala or in some other regions which have close nervous connections with the hippocampus.

Prior to the lesion experiments, the subject was primed with estrogen in the same manner as in the stimulation experiments, which consisted of 2 subcutaneous injection of $0.1 \mathrm{mg}$ estradiol benzoate in oil on consecutive day, and then the formation of $\left({ }^{14} \mathrm{C}\right)$-incorporated progesterone and estrogen labelling from $\left(1{ }^{14} \mathrm{C}\right)$ acetate by the ovarian homogenates, and the ovarian progesterone output were measured on the third day.

Large hemorrhagic follicles were found to be induced by electrical stimulation of the dorsal hippocampus after the bilateral lesioning of the stria terminalis as already mentioned in the first part of this study. In these cases, the progesterone labelling from $\left(1{ }^{-14} \mathrm{C}\right)$ acetate by the ovarian homogenates and the ovarian progesterone output considerably increased, while labelled estrogen showed almost no increase. In consequence, the $\mathrm{E} / \mathrm{P}$ ratio markedly declined. This fact may imply that the effects of hippocampal stimulation upon the progesterone formation in the ovary still remain to a good extent after the lesioning of the stria terminalis; and such effects are reflected upon the ovary by a pathway different from the stria terminalis.

In rabbits with lesions of the fornix, the amount of progesterone and estrogen labelling from $\left(1^{-14}\right)$ acetate by the ovarian homogenates following electrical stimulation of the dorsal hippocampus were lowered in amount compared to the control. The ovarian progesterone output decreased.

These facts show that the facilitatory effects of hippocampal stimulation upon the ovarian progesterone and estrogen formation are blocked by bilateral lesions of the dorsal fornix. This might be considered as a proof that such effects are exerted upon the ovary through the fornix. It is also implied that the hippocampus plays a major role in the production of steroid hormones in the ovary, but this mechanism needs to be further investigated.

After the arcuate nucleus was lesioned, electrical stimulation of the dorsal hippocampus exerted no effective influences upon the progesterone and estrogen formation in the ovary and ovarian progesterone output. This fact suggests that the effects of hippocampal stimulation upon the ovary are produced through the arcuate nucleus.

On the other hand the destruction of the dorsal fornix alone, without stimulating the hippocampus, was found to decrease the formation of $\left({ }^{14} \mathrm{C}\right)-$ incorporated progesterone and $\left({ }^{14} \mathrm{C}\right)$-incorporated estrogen labelling from $\left(1-{ }^{14} \mathrm{C}\right)$ acetate by the ovarian homogenates, and ovarian progesterone output compared to the intact cases. The destruction of the stria terminalis had no such decreasing effect when the hippocampus was not stimulated. These results were summarized in TABLE 6.

Though it is beyond the limits of the present data, it might be postulated that marked differences in the $\mathrm{E} / \mathrm{P}$ ratio between cases with bilateral lesions 
TABLE 6.

Effects of hippocampal stimulation upon ovulation and upon formation of progesterone and estrogen in the rabbit's ovary after lesioning the stria terminalis, periventricular arcuate nucleus of the hypothalamus and the fornix.

\begin{tabular}{|c|c|c|c|c|c|c|c|c|}
\hline \multirow[b]{2}{*}{$\begin{array}{l}\text { Site of } \\
\text { lesion }\end{array}$} & \multirow[b]{2}{*}{$\begin{array}{c}\text { DHPC } \\
\text { stimulation }\end{array}$} & \multirow[b]{2}{*}{$\stackrel{\vec{\Xi}}{\stackrel{\vec{J}}{\Xi}}$} & \multirow{2}{*}{$\begin{array}{l}\frac{\Xi}{0} \\
\frac{0}{3} \\
\frac{\pi}{3} \\
0\end{array}$} & \multirow[b]{2}{*}{ 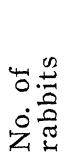 } & \multicolumn{2}{|c|}{ Formation } & \multirow[b]{2}{*}{$\mathrm{E} / \mathrm{P}$} & \multirow{2}{*}{$\begin{array}{c}\text { Ovarian } \\
\text { progesterone } \\
\text { output }\end{array}$} \\
\hline & & & & & $\begin{array}{l}\text { Proges- } \\
\text { terone } \\
\left(\mathrm{C}^{14}\right)\end{array}$ & $\begin{array}{c}\text { Estrogen } \\
\left(\mathrm{C}^{14}\right)\end{array}$ & & \\
\hline - & - & - & - & 5 & $100 \% *$ & $100 \% *$ & $100 \% * *$ & $100 \%$ \\
\hline- & + & 280 & + & 4 & 160 & 112 & 71 & 170 \\
\hline \multirow{2}{*}{$\begin{array}{c}\text { Stria } \\
\text { terminalis }\end{array}$} & - & - & - & 3 & 101 & 100 & 101 & 100 \\
\hline & + & 280 & \pm & 3 & 125 & 92 & 78 & 121 \\
\hline \multirow{2}{*}{ ARC } & - & - & - & 5 & 105 & 96 & 96 & 89 \\
\hline & + & 280 & - & 5 & 106 & 100 & 92 & 94 \\
\hline \multirow{2}{*}{$\begin{array}{l}\text { Dorsal } \\
\text { fornix }\end{array}$} & - & - & - & 4 & 91 & 92 & 103 & 85 \\
\hline & + & 280 & - & 4 & 92 & 96 & 106 & 79 \\
\hline \multirow{2}{*}{$\begin{array}{l}\text { Ventral } \\
\text { fornix }\end{array}$} & - & - & - & 1 & 90 & 96 & 113 & 91 \\
\hline & + & 280 & - & 2 & 92 & 96 & 106 & 81 \\
\hline \multirow{2}{*}{ Septum } & - & - & - & 1 & 92 & 104 & 119 & 79 \\
\hline & + & 280 & - & 2 & 91 & 88 & 96 & 85 \\
\hline
\end{tabular}

in the fornix and in the stria terminalis are due to the lowered activity of the hippocampus caused by blocking of the afferent impulses passing through the fornix.

The above observation on the effects of electrical stimulation and of localized lesions in the brain upon the formation of $\left({ }^{14} \mathrm{C}\right)$-incorporated progesterone and estrogen from $\left(1^{-14} \mathrm{C}\right)$ acetate in the ovary was made on a basis of statistical testification ( $t$-test) as shown in TABLE 7A (progesterone) and 7B (estrogen).

With reference to biosynthesis of ovarian steroid hormones, it has been reported that gonadotrophin has a stimulatory effect upon biosynthesis of ovarian sex steroids and that the amount of ovarian progesterone formation is closely related to the biological activity of a luteinizing hormone $(\mathrm{LH})^{6,23,24,25)}$. It was also observed in the present experiments as illustrated in Fig. 4 that progesterone labelling from $\left(1{ }^{14} \mathrm{C}\right)$ acetate by the ovarian homogenates and the ovarian progesterone output increased in proportion to the administered. dose of $\mathrm{LH}$. 
TABLE 7.

The incorporation values of progesterone $(A)$ and of estrogen $(B)$ from the $(1-14 C)$ acetate after the hippocampal, amygdalar or the arcuate stimulation in intact animals and after the hippocampal stimulation in animals with bilateral lesions either in the dorsal fornix (FX) or in the stria terminalis (ST).

(A)

\begin{tabular}{|c|c|c|c|c|c|}
\hline & Ovulation & $\mathrm{N}$ & Mean & S. D. & $\begin{array}{l}\text { Reliability of } \\
\text { differences*** }\end{array}$ \\
\hline $\begin{array}{l}\text { DHPC stimulation } \\
\text { Control }\end{array}$ & + & $\begin{array}{l}4 \\
5\end{array}$ & $\begin{array}{r}149 \\
93\end{array}$ & $\begin{array}{r} \pm 10.4 \\
\pm 2.0 \\
\end{array}$ & 0.05 \\
\hline $\begin{array}{l}\text { AMYG stimulation } \\
\text { Control }\end{array}$ & + & $\begin{array}{l}4 \\
5\end{array}$ & $\begin{array}{r}132 \\
93\end{array}$ & $\begin{array}{l} \pm 1.9 \\
\pm 2.0\end{array}$ & 0.05 \\
\hline $\begin{array}{l}\text { ARC stimulation } \\
\text { Control }\end{array}$ & + & $\begin{array}{l}3 \\
5\end{array}$ & $\begin{array}{r}132 \\
93\end{array}$ & $\begin{array}{l} \pm 1.7 \\
\pm 2.0\end{array}$ & 0.05 \\
\hline $\begin{array}{l}\text { DHPC stimulation } \\
\text { AMYG stimulation }\end{array}$ & $\begin{array}{l}+ \\
+\end{array}$ & $\begin{array}{l}4 \\
4\end{array}$ & $\begin{array}{l}149 \\
132\end{array}$ & $\begin{array}{l} \pm 10.4 \\
\pm 1.9 \\
\end{array}$ & 0.05 \\
\hline $\begin{array}{l}\text { DHPC stimulation } \\
\text { ARC stimulation }\end{array}$ & + & $\begin{array}{l}4 \\
3 \\
\end{array}$ & $\begin{array}{l}149 \\
132\end{array}$ & $\begin{array}{r} \pm 10.9 \\
\pm 1.7 \\
\end{array}$ & 0.05 \\
\hline $\begin{array}{l}\text { AMYG stimulation } \\
\text { ARC stimulation }\end{array}$ & + & $\begin{array}{l}4 \\
3\end{array}$ & $\begin{array}{l}132 \\
132\end{array}$ & $\begin{array}{l} \pm 1.9 \\
\pm 1.7\end{array}$ & NS \\
\hline $\begin{array}{l}\text { DHPC stimulation after FX lesion } \\
\text { Control }\end{array}$ & - & $\begin{array}{l}4 \\
5\end{array}$ & $\begin{array}{l}79 \\
93\end{array}$ & $\begin{array}{l} \pm 6.8 \\
\pm 2.0\end{array}$ & 0.05 \\
\hline $\begin{array}{l}\text { DHPC stimulation after ST lesion } \\
\text { Control }\end{array}$ & \pm & $\begin{array}{l}3 \\
5\end{array}$ & $\begin{array}{r}115 \\
93\end{array}$ & $\begin{array}{l} \pm 3.8 \\
\pm 2.0 \\
\end{array}$ & 0.05 \\
\hline $\begin{array}{l}\text { DHPC stimulation after FX lesion } \\
\text { DHPC stimulation }\end{array}$ & $\overline{+}$ & $\begin{array}{l}4 \\
5\end{array}$ & $\begin{array}{r}79 \\
149 \\
\end{array}$ & $\begin{array}{r} \pm 6.8 \\
\pm 10.4 \\
\end{array}$ & 0.05 \\
\hline $\begin{array}{l}\text { DHPC stimulation after ST lesion } \\
\text { DHPC stimulation }\end{array}$ & \pm & $\begin{array}{l}3 \\
4\end{array}$ & $\begin{array}{l}115 \\
149\end{array}$ & $\begin{array}{l} \pm 3.8 \\
\pm 10.4 \\
\end{array}$ & 0.05 \\
\hline $\begin{array}{l}\text { DHPC stimulation after FX lesion } \\
\text { DHPC stimulation after ST lesion }\end{array}$ & $\overline{-}$ & $\begin{array}{l}4 \\
3\end{array}$ & $\begin{array}{r}79 \\
115 \\
\end{array}$ & $\begin{array}{l} \pm 6.8 \\
\pm 3.8 \\
\end{array}$ & 0.05 \\
\hline
\end{tabular}

(B)

\begin{tabular}{|c|c|c|c|c|c|}
\hline & Ovulation & $\mathrm{N}$ & Mean & S.D. & $\begin{array}{l}\text { Reliability of } \\
\text { differences*** }\end{array}$ \\
\hline $\begin{array}{l}\text { DHPC stimulation } \\
\text { Control }\end{array}$ & + & $\begin{array}{l}4 \\
5\end{array}$ & $\begin{array}{l}28 \\
25\end{array}$ & $\begin{array}{l} \pm 1.3 \\
\pm 0.8\end{array}$ & 0.05 \\
\hline $\begin{array}{l}\text { AMYG stimulation } \\
\text { Control }\end{array}$ & + & 4 & 29 & $\begin{array}{l} \pm 1.9 \\
\pm 0.8\end{array}$ & 0.05 \\
\hline $\begin{array}{l}\text { ARC stimulation } \\
\text { Control }\end{array}$ & + & $\begin{array}{l}3 \\
5 \\
\end{array}$ & $\begin{array}{l}26 \\
25 \\
\end{array}$ & $\begin{array}{l} \pm 0.8 \\
\pm 0.8\end{array}$ & NS \\
\hline $\begin{array}{l}\text { DHPC stimulation } \\
\text { AMYG stimulation }\end{array}$ & + & $\begin{array}{l}4 \\
4\end{array}$ & $\begin{array}{l}28 \\
29\end{array}$ & $\begin{array}{l} \pm 1.3 \\
\pm 1.9\end{array}$ & NS \\
\hline $\begin{array}{l}\text { DHPC stimulation } \\
\text { ARC stimulation }\end{array}$ & + & $\begin{array}{l}4 \\
3\end{array}$ & $\begin{array}{l}28 \\
26\end{array}$ & $\begin{array}{l} \pm 1.3 \\
\pm 0.8\end{array}$ & NS \\
\hline $\begin{array}{l}\text { AMYG stimulation } \\
\text { ARC stimulation }\end{array}$ & + & $\begin{array}{l}4 \\
3\end{array}$ & $\begin{array}{l}29 \\
26\end{array}$ & $\begin{array}{l} \pm 1.9 \\
\pm 0.8\end{array}$ & 0.05 \\
\hline $\begin{array}{l}\text { DHPC stimulation after FX lesion } \\
\text { Control }\end{array}$ & - & $\begin{array}{l}4 \\
5\end{array}$ & $\begin{array}{l}23 \\
25\end{array}$ & $\begin{array}{l} \pm 1.7 \\
\pm 0.8\end{array}$ & 0.05 \\
\hline $\begin{array}{l}\text { DHPC stimulation after ST lesion } \\
\text { Control }\end{array}$ & \pm & $\begin{array}{l}3 \\
5\end{array}$ & $\begin{array}{l}24 \\
25\end{array}$ & $\begin{array}{l} \pm 0.5 \\
\pm 0.8\end{array}$ & 0.05 \\
\hline $\begin{array}{l}\text { DHPC stimulation after FX lesion } \\
\text { DHPC stimulation }\end{array}$ & $\bar{t}$ & $\begin{array}{l}4 \\
5\end{array}$ & $\begin{array}{l}23 \\
28\end{array}$ & $\begin{array}{l} \pm 1.7 \\
\pm 1.3\end{array}$ & NS \\
\hline $\begin{array}{l}\text { DHPC stimulation after ST lesion } \\
\text { DHPC stimulation }\end{array}$ & \pm & $\begin{array}{l}3 \\
4\end{array}$ & 24 & $\begin{array}{l} \pm 0.5 \\
\pm 1.3\end{array}$ & 0.05 \\
\hline $\begin{array}{l}\text { DHPC stimulation after FX lesion } \\
\text { DHPC stimulation after ST lesion }\end{array}$ & \pm & $\begin{array}{l}4 \\
3\end{array}$ & 24 & $\begin{array}{l} \pm 1.7 \\
\pm 0.5\end{array}$ & NS \\
\hline
\end{tabular}

Abbreviation: ${ }^{* * *}: t$-test for each pair indicated in the first column. 

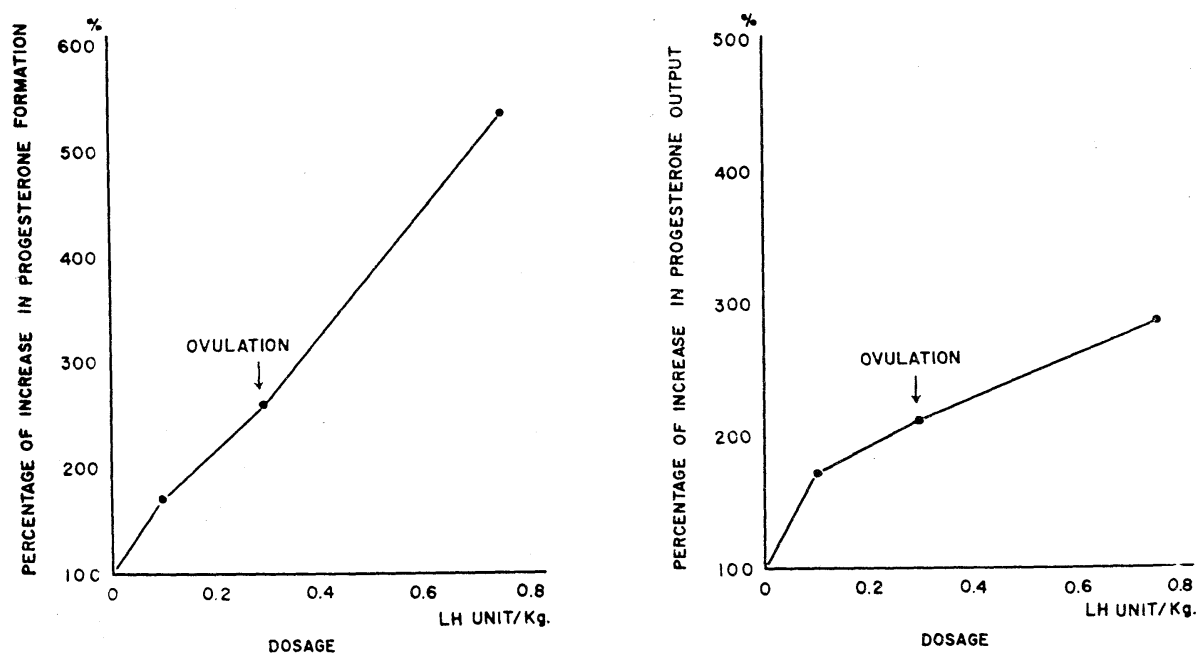

FIG. 4. Effects of $\mathrm{LH}$ on the formation of progesterone from $\left(1-{ }^{14} \mathrm{C}\right)$ acetate by ovarian homogenates and on ovarian progesterone output. Note: The ovaries were removed from the rabbits 60 minutes after the administration of $\mathrm{LH}$ (the total dose of the stated units given as a single intravenous injection). LH preparation (Lot No. R 377279) was supplied by Armour Veterinary Laboratories, U.S. A.

Consequently, the inducement of ovulation by electrical stimulation of the hippocampus, amygdala and the arcuate nucleus and the subsequent increased biosynthesis of progesterone in the ovary might suggest that excitation of appropriate sites within the brain increases LH-release from the adenohypophysis. This is in accord with the findings of SAWYER et al.6,26) who investigated the relation between the electrical stimulation of amygdala, coital stimuli, and the biological activity of $\mathrm{LH}$.

On the basis of these facts, it may perhaps be accepted that gonadotrophin-release from adenohypophysis varies with different stimulation sites within the brain and that the hippocampus is regulating the discharge of the ovulating hormone from the anterior hypophysis via the hypothalamus as a higher center.

\section{DISCUSSION}

According to the experiments by KAWAKAMI et al.27,28), there was a seesaw relationship of EEG activity between the amygdala and the hippocampus throughout the whole period of the sexual cycle. Namely, the activity of the hippocampus decreased at the stage of estrogen dominance over progesterone (estrous stage) and increased at the stage of progesterone dominance over estrogen (post-coital stage and pregnancy), while the excitability of the amygdala increased at the estrous stage and decreased at the post-coital and 
the pregnant stage. Also the hippocampal activity rose after intravenous injection of LH $(0.3-0.5 \mu)$ or HCG $(300-400 \mu)$ and declined after administration of FSH $(150-250 \mu)$ or PMS $(300-400 \mu)$. In contrast to the facilitatory effects of $\mathrm{LH}$ and HCG upon the hippocampal activity, the amygdalar activity was depressed after the injection of the same amounts of LH or HCG. Further, the same relationship was observed by KAWAKAMI and TERASAWA ${ }^{8)}$ in alterations of the amplitude and latency of the potentials evoked from the periventricular arcuate nucleus in the hypothalamus by stimulation of the hippocampus and the amygdala. In the course of the estrous cycle, the amplitude of both negative and positive responses of the periventricular arcuate nucleus to the hippocampal stimulation decreased during estrus and increased during progesterone dominance over estrogen as exhibited during the rebound stage or the anestrous stage. The response, either positive or negative, in the arcuate nucleus by the amygdalar stimulation showed relations inverted to those of the hippocampus.

Excitation of the hippocampus facilitates the release of ovulatory hormones from the adenohypophysis via the basal hypothalamus. These discharged hormones yield both an increased production and output of ovarian progesterone. This increased concentration of the progesterone in the systemic circulation elevates the excitability of the hippocampus, so that the afferent impulses can more easily induce the elevation of hippocampal activity. This result suggests the existence of a functional circuit between the hippocampus and the ovary having positive feedback control of the ovarian progesterone production and output.

Conversely, there may be negative feedback control of the production and output of progesterone between the amygdaloid activity and the ovary. That is, the ovulatory hormone release from the pituitary gland caused by amygdalar activation induces progesterone secretion from the ovary, though in a less degree that by hippocampal activation, and consequently lowers the excitability of the amygdala.

\section{SUMMARY}

By using the New Zealand White rabbits with chronically implanted bipolar electrodes in the several parts of the brain, studies of the influences of electrical stimulation of the limbic system and the hypothalamus upon progesterone and estrogen formation in the ovary and ovarian progesterone output were carried out. Effects were studied through observations upon inducement of ovulation and upon incorporation of radioactivity into progesterone and estrogen (estradiol+estrone) by the ovarian homogenates in vitro with $\left(1-{ }^{14} \mathrm{C}\right)$ acetate.

The implanted rabbits were primed with estradiol benzoate in oil $(0.1 \mathrm{mg}$ 
s. c.) for 2 days prior to stimulation to ensure an estrous state. Electrical stimulation, consisting of monophasic square wave pulses, was delivered unilaterally for $30 \mathrm{~min}$., $60 \mathrm{sec}$. on and $60 \mathrm{sec}$. off, $260-280 \mu \mathrm{A}$, at $0.1 \mathrm{msec}$ duration, $60 \mathrm{cps}$. The results were as follows:

1. Ovulation was induced by $260-280 \mu \mathrm{A}$ electrical stimulation of the hippocampus in the estrogen primed rabbits in the 20 out of 30 cases. Almost no differences were observed between the effect of electrical stimulation of the dorsal and the ventral parts of the hippocampus. Similar results were observed in the effects of stimulation upon the intermediate nucleus of the amygdala and the periventricular arcuate nucleus. The ovulation induced thereby was blocked by bilateral lesions of the dorsal or the ventral fornix, by a massive lesion of the septum, or by a localized lesion of the periventricular arcuate nucleus including the adjacent regions. On the contrary, when the stria terminalis was damaged bilaterally, hippocampal stimulation still produced hemorrhagic follicles in the ovaries.

2. Electrical stimulation of the hippocampus enhanced progesterone formation in the ovary more than that of the amygdala and the periventricular arcuate nucleus. But, it showed an unappreciable difference in estrogen formation among these three regions. The ratio of $\left({ }^{14} \mathrm{C}\right)$-incorporated estrogen to $\left({ }^{14} \mathrm{C}\right)$ incorporated progesterone $(\mathrm{E} / \mathrm{P})$ showed a lower value in the hippocampus than in the other areas.

In respect to progesterone labelling from $\left(1-{ }^{14} \mathrm{C}\right)$ acetate by the ovarian homogenates, the ovarian progesterone output and the $\mathrm{E} / \mathrm{P}$ ratio, little difference was observed between the effect of electrical stimulation of the amygdala and the periventricular arcuate nucleus of the hypothalamus including the posterior tuberal region. When the dorsal or the ventral fornix was damaged bilaterally, the synthesis of ovarian progesterone and estrogen and the ovarian progesterone output were lower than those of the control without regard to hippocampal stimulation. But in the animals with lesion in bilateral stria terminalis hippocampal stimulation retained the facilitatory effect upon the formation of progesterone and estrogen and the progesterone output. These findings may suggest that the effect of hippocampal stimulation upon the ovary was exerted through the fornix and the basal hypothalamus including the arcuate nucleus, and not through the stria terminalis.

This experiment was supported by a grant from the National Institute of Health, U.S. Public Health Service (NB-03860-4) and a grant from the Ministry of Education, Japan.

\section{REFERENCES}

1) Kolkegami, H., Yamada, T. And Usui, K. (1954) Stimulation of amygdaloid nuclei and periamygdaloid cortex with special reference to its effects on uterine movements and ovulation. Fol. psychiatr. neurol., 8: 7-31. 
2) Bunn, J. P. And Everett, J. W. (1951) Ovulation in persistent-estrous rats after electrical stimulation of the brain. Proc. Soc. Expl. Biol. Med., 96: 369-371.

3) Shealy, C. N. and Peele, T. L. (1957) Studies on amygdaloid nucleus of cat. J. Neurophysiol., $20: 125-139$.

4) SAwyer, C.H. From private communication.

5) Elwers, M. ANd Critchlow, V. (1961) Precocious ovarian stimulation following interruption of stria terminalis. Am. J. Physiol., $201: 281-284$.

6) Hayward, J.N., Hilliard, J. And Sawyer, C.H. (1964) Time of release of pituitary gonadotropin induced by electrical stimulation of the rabbit brain. Endocrinology, 74 : 108-113.

7) Kawakami, M., Terasawa, E., Tsuchihashi, S. and Yamanaka, K. Differential control of sex hormone upon brain activity in rabbit and its physiological significance. (in press)

8) Kawakami, M., Terasawa, E., Tsuchinashi, S. and Uemura, T. (1965) Sex hormone sensitive components in the rabbit brain and their physiological significance. U.S.-Japan Joint Conference for "Dynamics of Steroid Hormones ". (U.S.Japan Cooperative Science Program), P. 1-4.

9) Sawyer, C. H., Everett, J. W. And Green, J.D. (1954) The rabbit diencephalon in stereotaxic coordinates. J. Comp. Neurol., 101:801-824.

10) Seto, K., Sekiguchi, M., Ushikoshi, I. And Umezu, M. (1964) The effects of the pituitary gland on the metabolism of testicles. (in Japanese) Tohoku J. Zootech. Scien., $14: 39$.

11) Roberts, S., Seto, K. And Hanking, B.H. (1962) Regulation of cerebral metabolism. J. Neuroche., 9 : 493-501.

12) Klüver, H. ANd Bucy, P.C. (1937) "Psychic blindness" and other symptoms following bilateral temporal lobectomy on rhesus monkeys. Am. J. Physiol., 119: 352-353.

13) Schreiner, L. And Kling, A. (1953) Behavioral changes following rhinencephalic injury in cat. J. Neurophysiol., $16: 643-659$.

14) Green, J.D., Clemente, C.D. and De Groot, J. (1957) Rhinencephalic lesions and behavior in cats; an analysis of the KLÜVER-BUCY syndrome with particular reference to normal and abnormal sexual behavior. J. Comp. Neurol., 108: 505-545.

15) Yamada, T. ANd Greer, M. A. (1960) The effect of bilateral ablation of the amygdala on endocrine function in the rat. Endocrinology, 66:565-574.

16) Crosby, E. C., Humphrey, T. And Lauer, E. W. (1962) Correlative anatomy of the nervous system. New York, The MacMillan Company.

17) BAn, T. (1964) The hypothalamus, especially on its fiber connections, and the septo-preoptico-hypothalamic system. Med. J. Osaka Univ., 15:1-83.

18) Kolkegami, H. (1963) Amygdala and other related limbic structures; experimental studies on the anatomy and function. Acta med. biol., 10 : 161-277.

19) Kolkegami, H. (1964) Amygdala and other related limbic structures; experimental studies on the anatomy and function. Acta med. biol., 12:73-266.

20) GLoor, P. (1956) Telencephalic influences upon the hypothalamus. pp. 74-113 in: Hypothalamic-hypophysial interrelationship. ed. by W.S. Fields, Illinois, C. Thomas Publisher.

21) Green, J.D. And Adey, W.R. (1956) Electrophysiological studies of hippocampal connections and excitability. EEG Clin. Neurophysiol., 8 : 245-262.

22) Korkegami, H. (1962) The anatomical relation between limbic system and activity. (in Japanese) Brain and, Nerve, $14: 541-549$.

23) Hilliard, J., Archibald, D. And Sawyer, C. H. (1963) Gonadotropin activation of preovulatory synthesis and release of progestin in the rabbit. Endocrinology, 
$72: 59-66$.

24) Rice, B. F., Hammerstein, J. And Savard, K. (1964) Steroid hormone formation in the human ovary: 11 action of gonadotropins in vitro in the corpus luteum. J. Clin. End. and Met., 24 : 606-615.

25) Hilliard, J. and Sawyer, C.H. (1964) Synthesis and release of progestin by rabbit ovary in vivo. Proc. 1st Intern. Cong. Hormone Steroids, 1: P. 264-272.

26) Hilliard, J., Hayward, J. N. And Sawyer, C. H. (1964) Postcoital patterns of secretion of pituitary gonadotropin and ovarian progestin in the rabbit. Endocrinology, $75 ; 957-963$.

27) Kawakami, M. and Terasawa, E. (1965) Studies on brain activity and conduction of synapsis in estrous cats and rabbits. J. Physiol. Soc. Jap., $27: 86$.

28) Terasawa, E. And Kawakami, M. (1965) Differential control of oxytocin upon the evoked potential in the hypothalamus. Proc. 23rd Intern. Cong. Physiol. Sci. Abstr., P. 430. 